\title{
Glycaemic Control in Diabetes
}

\author{
D. Müller-Wieland, J. Brandts, M. Verket, N. Marx, and K. Schütt
}

\section{Contents}

1 Cardiovascular Risk in Diabetes ......................................... 48

2 Microvascular End-Organ Damage and Cardiovascular Risk ....................... 49

3 Role of Hyperglycaemia for Micro- and Macro-vascular Complications ............... 50

4 Role of Hyperglycaemia in Reducing Vascular Risks in Type 1 Diabetes .............. 51

5 Efficacy Trials of Glucose Lowering in Type 2 Diabetes ........................ 52

6 Cardiovascular Safety Studies in Type 2 Diabetes ............................. 53

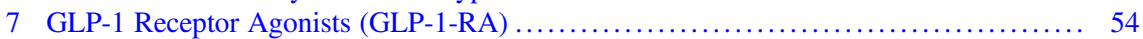

8 SGLT (Sodium Glucose Transporter) 2 Inhibitors ........................... 58

9 Mechanisms of Action for Cardio-Renal Protection Through SGLT-2 Inhibition ........ 62

10 Change in Guidelines and Clinical Recommendations ........................... 64

11 Perspectives: Fat Partitioning as a New Target of Diabetes Drugs .................. 65

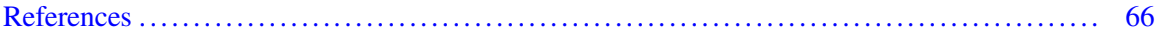

\section{Abstract}

Reduction of glucose is the hallmark of diabetes therapy proven to reduce microand macro-vascular risk in patients with type 1 diabetes. However glucoselowering efficacy trials in type 2 diabetes didn't show major cardiovascular benefit. Then, a paradigm change in the treatment of patients with type 2 diabetes has emerged due to the introduction of new blood glucose-lowering agents. Cardiovascular endpoint studies have proven HbAlc-independent cardioprotective effects for GLP-1 receptor agonists and SGLT-2 inhibitors. Furthermore, SGLT-2 inhibitors reduce the risk for heart failure and chronic kidney disease. Mechanisms for these blood glucose independent drug targetrelated effects are still an enigma. Recent research has shown that GLP-1 receptor agonists might have anti-inflammatory and plaque stabilising effects whereas

D. Müller-Wieland $(\triangle) \cdot$ J. Brandts $\cdot$ M. Verket $\cdot$ N. Marx $\cdot$ K. Schütt Department of Medicine I, University Hospital RWTH Aachen, Aachen, Germany e-mail: dirmueller@ukaachen.de 
SGLT-2 inhibitors primarily reduce pre- and after-load of the heart and increase work load efficiency of the heart. In addition, reduction of intraglomerular pressure, improved energy supply chains and water regulation appear to be major mechanisms for renoprotection by SGLT-2 inhibitors. These studies and observations have led to recent changes in clinical recommendations and treatment guidelines for type 2 diabetes. In patients with high or very high cardio-renal risk, SGLT-2 inhibitors or GLP-1 receptor agonists have a preferred recommendation independent of baseline HbA1c levels due to cardioprotection. In patients with chronic heart failure, chronic kidney disease or at respective risks SGLT2 inhibitors are the preferred choice. Therefore, the treatment paradigm of glucose control in diabetes has changed towards using diabetes drugs with evidencebased organ protection improving clinical prognosis.

\section{Keywords}

GLP-1 receptor agonists · Heart failure - SGLT-2 inhibitors · Type 2 diabetes

Risks for clinical complications of micro- and macro-vascular disease appear to be increased in patients with type 1 and type 2 diabetes. Whereas the relation between elevated glucose levels and microvascular complications seems to be directly correlated and generally specific for diabetes. The relation to macrovascular risk, however, is more complex, multifactorial and not exclusive for diabetes. The link between type 2 diabetes and macrovascular risk is extending beyond glucose levels and may be related to obesity, fat partitioning, and insulin resistance, a concert also called metabolic syndrome.

In the following, we provide epidemiological evidence for increased vascular risk in diabetes, discuss the role of glucose control and introduce the cardiovascular outcome trials (CVOTs) for GLP-1 receptor agonists and SGLT-2-inhibitors. These trials provide direct clinical evidence for cardio-renal protection, independent of baseline HbA1c levels, leading to major changes in treatment algorithms in current guidelines. In conclusion, we will allude to the emerging of efficient obesity treatments, which might ultimately alter pathophysiological features of the metabolic syndrome and potential targets for atherosclerosis.

\section{$1 \quad$ Cardiovascular Risk in Diabetes}

The Emerging Risk Factors Collaboration analysed individual data from a total of more than one million people with more than 135,000 deaths (Danesh 2015). The relative risk of mortality was increased approximately twofold in the presence of diabetes or myocardial infarction, almost fourfold for the combination and almost sevenfold for additional stroke.

In the Swedish National Diabetes Registry, 318,083 patients with type 2 diabetes were compared with nearly 1.6 million matched controls over 5-6 years for 
cardiovascular endpoints and all-cause mortality (Sattar et al. 2019). Patients diagnosed with diabetes before age 40 years had on average a mean twofold increased risk of all-cause mortality, 2.72-fold increased risk of cardiovascular mortality, 4.77-fold increased risk of heart failure and 4.33-fold increased coronary risk. The risk was age-dependent and was no longer increased in a person older than 80 years old. Due to the increased risk of mortality in patients with diabetes, a database of care providers was used to analyse its relative risk in 31,987 newly diagnosed patients with diabetes compared to 162,656 controls over a 9.5-year period (Zucker et al. 2017). During this period, $14 \%$ of patients with diabetes died, but only $8 \%$ of matched controls without diabetes died. When adjusted for age, sex, socioeconomic status, obesity, smoking and comorbidities incident diabetes was associated with a $38 \%$ higher relative risk of all-cause mortality. A systematic review summarised published data over 10 years (2007-2017) on the prevalence of cardiovascular disease in nearly five million people with diabetes (Einarson et al. 2018). 32.2\% of patients with type 2 diabetes had clinically manifest cardiovascular disease, $14.9 \%$ had clinically manifest heart failure and $10 \%$ had myocardial infarction. In $9.9 \%$ of cases, cardiovascular disease was the cause of death, which represented $50.3 \%$ of the total death rate.

Patients with type 1 diabetes are notably well analysed in the Swedish national registry. In this registry, the patient's mean age between 1998 and 2011 was 35.8 years. Patients were followed for a mean of about 8 years and compared to random control individuals by age, sex and region. Patients with type 1 diabetes had a significantly higher overall mortality of $8.0 \%$ compared to $2.9 \%$ in subjects without diabetes, corresponding to a relative risk of 3.52 (Lind et al. 2014). Recently, this registry analysed the prognostic significance of 17 risk factors for death, i.e. mortality from all causes, acute myocardial infarction or stroke. Of the 32,611 patients with type 1 diabetes in this Swedish registry cohort, 5.5\% died over the course of 10.4 years. The strongest predictors of death and cardiovascular endpoints were $\mathrm{HbA1c}$, albuminuria, diabetes duration, systolic blood pressure and blood LDL cholesterol concentration. An increase of approximately $1.0 \%$ in $\mathrm{HbA} 1 \mathrm{c}$ was associated with a $22 \%$ higher risk. Furthermore, HbA1c levels $<7.0 \%$ were associated with a significantly lower risk (Rawshani et al. 2019).

\section{Microvascular End-Organ Damage and Cardiovascular Risk}

Microvascular alterations with increased risk for end-organ damage, such as retino-, nephro- and neuropathy, are increased in diabetes. The duration and intensity of hyperglycaemia appear to play a major role. One clinical relevant question for cardiovascular risk stratification is whether microvascular "end-organ damage" in turn also increases the risk for macrovascular complications. To address this question, a population-based cohort study of 49,027 patients with type 2 diabetes analysed the association between the combined endpoint consisting of cardiovascular death, nonfatal myocardial infarction, stroke and the cumulative presence of retinal, nephro- and peripheral neuropathy over 5.5 years (Brownrigg et al. 2016). 
Each microvascular end-organ damage was associated with an increased cardiovascular risk by approximately $35-40 \%$. The accumulation of relative cardiovascular risk in the presence of one, two or three microvascular diseases increased by $32 \%$, $62 \%$ and $99 \%$, respectively. Similar trends were seen for cardiovascular death, all-cause mortality and hospitalisation for heart failure.

Therefore, microvascular end-organ damage appears to indicate or even mediate increased cardiovascular risk. In the case of a possible mediating role, common links discussed include damage to the microvascular pathway including endothelial dysfunction. This is clinically relevant because microvascular complications and endothelial dysfunction can be directly influenced by elevated blood glucose concentrations. However, the incidence as well as progression of end-organ damage is also modulated by other factors, such as increased blood pressure, smoking, etc. (Climie et al. 2019; Ziegler et al. 2020).

\section{Role of Hyperglycaemia for Micro- and Macro-vascular Complications}

Diabetes is not only associated with an increased micro- and macro-vascular risk, but also with a variety of non-vascular changes or syndromes. Since diabetes per se is currently (still) defined by hyperglycaemia, we will briefly discuss the possible roles of hyperglycaemia as an indicator, mediator or modulator of late complications.

Microvascular complications seem to be essentially caused by hyperglycaemia. However, it has to recurrently persist to display clinical consequences or complications. Though, macrovascular complications are more likely to be caused by other factors, such as insulin resistance, altered fat ectopic accumulation (e.g. in the liver, skeletal muscle or heart - see below), dyslipidaemia, hypertension, hypercoagulability, etc. Therefore, these complications are not diabetes-specific and can occur even before diagnosis, e.g. prediabetes or metabolic syndrome (Rask-Madsen and Kahn 2012; Kahn et al. 2019). Numerous non-vascular changes are not specific to diabetes, but are observed more frequently in patients with diabetes, e.g. fatty liver, COPD, certain forms of cancer, depression, cognitive disorders, osteoporosis, disorders of the gastrointestinal tract as well as the genitourinary system, skin changes, increased risk of infection, cheiroarthropathies, etc.

The role of hyperglycaemia in the many facets of vascular and other late complications may vary, i.e. hyperglycaemia may be a mediator, a modulator or just an indicator of increased risk. Moreover, the "damaging thresholds" of hyperglycaemia fluctuate for different micro-, macro- and non-vascular complications. One reason for this may also be that functional loss of the target organ, like retina or glomerular filtration, is not only a direct consequence of microvascular changes, but also involves other non-vascular cells, e.g. pericytes, podocytes, etc. Hitherto, it remains unclear how hyperglycaemia can exactly cause microvascular or organ damage. One common hypothesis is that hyperglycaemia leads to epigenetic and thus long-term changes that are unlikely to be quickly reversible by good blood glucose control. Furthermore, metabolically oriented 
hypotheses assume that the function, synthesis and degradation of proteins through glycosylation or increased substrate supply for various metabolic pathways can indirectly or directly lead to cell and tissue disorders, e.g. endothelium, nerve cells, proteins in the blood, e.g. of coagulation factors as well as connective tissue proteins. The formation of advanced glycosylation end-products (AGE), increase in sorbitol or hexosamine metabolic pathways, intracellular activation of protein kinase $\mathrm{C}$ through an increase in diacylglycerol as well as other signalling cascades and gene regulatory mechanisms play a decisive role. In addition to glycosylation, the formation of reactive oxygen radicals and superoxides in the mitochondria could also have a key biological role in this complex process in a subcellular level. Clinically, it is important to note that glycosylation is usually irreversible, i.e. a near-normal blood glucose control does not acutely lead to a "dissolution" of already manifested alterations, but ensures that no further changes occur and that the cellular metabolism and the pattern of modified proteins reconstitute themselves over (long) time. Therefore, early and long-term control of blood glucose metabolism, especially in younger people who still have a long life expectancy, remains a clinical concept.

In this respect, it is recognised that early and sufficient glucose control may reduce the incidence and possible progression of vascular disease. However, dissolution and cure of already established glucose-related damage, as it occurs in older patients with type 2 diabetes, longer disease duration, or prevalent atherosclerotic cardiovascular disease, appears not feasible. Therefore, it is a milestone that new drug classes like GLP-1 receptor agonists and SGLT-2-inhibitors have HbA1cindependent complication-protective effects even in the short-term.

\section{Role of Hyperglycaemia in Reducing Vascular Risks in Type 1 Diabetes}

The hypothesis that therapeutic lowering of HbA1c and thus hyperglycaemia is associated with a reduction in late complications has been proven in patients with type 1 diabetes by the DCCT (Diabetes Control and Complications Trial) study. The DCCT study has shown as a proof-of-concept study that early and effective blood glucose lowering can significantly reduce the incidence and progression of microvascular complications in patients with type 1 diabetes; similar associations were found in further follow-up for macrovascular complications. It could be that macrovascular complications or atherosclerosis develops quite differently in type 2 diabetes than in type 1 diabetes, or that the DCCT study examined very young patients in whom the many other modulators of vascular risk (see above) do not yet have the decisive significance as in later adulthood or in most patients with type 2 diabetes. The DCCT study was initiated by the National Institute of Diabetes and Digestive and Kidney Disease (NIDDK) from 1983-1993 with 1,441 patients with type 1 diabetes mellitus and became a milestone for the treatment of patients with type 1 diabetes. This study showed that intensified insulin therapy lasting a mean of 6.5 years halved the incidence and progression of microvascular sequelae compared to conventional therapy, which was associated with a significant difference in 
HbA1c (The Diabetes Control and Complication Trial 1993). After a mean followup of 17 years in $>90 \%$ of the initially enrolled patients, the cardiovascular risk was significantly reduced by $42 \%$ in the intensified treatment group, and the reduction in HbA1c was significantly associated with this (The Diabetes Control and Complication Trial/Epidemiology of Diabetes Interventions and Complications (DCCT/ EDIC) Study Research Group 2005). In the EDIC (Epidemiology of Diabetes Interventions and Complications) study, patients have now been followed up for over 30 years. In summary, after 30 years the following was concluded (Zinman et al. 2014):

- Hyperglycaemia is the primary modifiable mediator of late complications in type 1 diabetes.

- Near-normal glucose control reduces the incidence and progression of microvascular complications, such as retinopathy, nephropathy and neuropathy.

- Intensive diabetes therapy reduces cardiovascular complications in type 1 diabetes.

Recently, the concept and importance of good glycaemic control has been further explored and discussed in the DCCT/EDIC trial in relation to cardiovascular complications (Riddle and Gerstein 2019). A mediation analysis and multivariable models show (Bebu et al. 2019) that the quality of adjustment of traditional risk factors accounts for only about 50\% of the cardioprotective effect of improved metabolic control. HbAlc can be an indicator for changes in other parameters, e.g. lipids, albuminuria, etc., but this explains $<10 \%$ of the effect. Therefore, about $40 \%$ of the cardioprotective effect remains for HbA1c or elevated glucose concentrations per se. Thus, the therapeutic concept is further confirmed that HbA1c lowering in patients with type 1 diabetes is clinically relevant for reducing the incidence and progression of micro- and macro-vascular late complications. The future must show whether the predictability of the clinical prognosis for late complications through other parameters, such as the duration of glucose control in the desired range, so-called time in range (TiR), has a benefit alongside or in addition to HbA1c (Battelino et al. 2019).

\section{$5 \quad$ Efficacy Trials of Glucose Lowering in Type 2 Diabetes}

The UKPDS trial randomly assigned 5,102 patients with newly diagnosed type 2 diabetes to intensive glucose control with sulphonylurea or insulin or to management with diet alone. Those who were overweight at study entry also could be randomised in the intensive arm to receive metformin (UKPDS 33 1998; Stratton et al. 2000). In the insulin and sulphonylurea analyses, HbA1c levels of $7.0 \%$ vs. $7.9 \%$, respectively, were significantly associated with a relatively decreased risk for a composite endpoint of all diabetes-related complications by $12 \%$, and microvascular disease risk by $25 \%$ during an average follow-up of 10 years. Intensive control showed a trend towards decreased risk of myocardial 
infarction and no effect on stroke. In overweight patients, metformin yielded better glucose control (HbAlc 7.4\% vs. 8.0\%) and significantly decreased relative risk for myocardial infarction by $39 \%$ and for all-cause mortality by $36 \%$. The long-term follow-up of the UKPDS trial cohort suggests a "legacy" of cardiovascular benefit of early and tight glycaemic control. Similarly, this was a finding observed in the longterm follow-up of the Diabetes Control and Complications Trial (DCCT) in patients with type 1 diabetes. However, the results of the following efficacy trials in patients with longer diabetes duration were not so promising.

The ACCORD trial compared intensive vs. standard glucose control in 10,251 patients with type 2 diabetes who had high CVD risk, achieving an HbA1c of $6.4 \%$ vs. $7.5 \%$ (Gerstein et al. 2008). This trial was halted early due to an excess of all-cause mortality in the intensively treated group ( 257 vs. 203 events; $p=0.04$ ), with no significant difference observed in the primary composite cardiovascular disease endpoint of cardiovascular death, myocardial infarction, and stroke. The ADVANCE trial enrolled 11,140 patients with type 2 diabetes who had cardiovascular disease, microvascular disease, or another vascular risk factor at study entry (Heller 2009). Patients randomly received intensive glucose control with gliclazide plus other drugs in the intensive arm, compared with standard control with other drugs. Similar to the ACCORD trial, the ADVANCE trial did not show statistically significant improvement in the composite outcome of cardiovascular death, myocardial infarction, and stroke with intensive control (achieved HbA1c of $6.4 \%$ vs. $7.0 \%$ ), despite having 1,147 events. In the Veterans Affairs Diabetes Trial (VADT), 1791 US veterans with type 2 diabetes and inadequate glucose control randomly received either intensive or standard glucose control (Duckworth et al. 2009). Despite a wide separation in glucose control levels (HbA1c of $6.9 \%$ vs. $8.4 \%$ ) and ascertainment of 499 primary major adverse cardiovascular events (MACEs), this trial also found no significant improvement in cardiovascular outcomes with intensive control. From post hoc analyses of data for each of these trials and supported by the long-term observations from UKPDS in patients with newly diagnosed diabetes at study entry, the concept has emerged that more intensive glycaemic control may be safer and may have more favourable cardiovascular effects when used earlier in the course of diabetes. In contrast, patients with a longer duration of type 2 diabetes and more intense glucose control has only resulted in modest impact on cardiovascular events over time. In this respect, cardiovascular safety studies are of interest, because they aim to assess the safety of a new drug and possibly a mainly glucose independent superiority effect on predefined endpoints, like cardiovascular or renal complications.

\section{Cardiovascular Safety Studies in Type 2 Diabetes}

Cardiovascular safety studies are designed in such a way that the substance under investigation is compared with placebo, but that the risk parameter to be influenced, in this case HbA1c or blood glucose, should also be comparably reduced in the placebo arm of the study according to study protocol to achieve glycaemic 
equipoise. Therefore, this design tests not only the safety of a therapeutic molecule, but also its effect on cardiovascular risk, independent of blood glucose-lowering. Overall, insulin glargine (The ORIGIN Trial Investigators 2012), insulin degludec (Marso et al. 2017) as well as acarbose (Holman et al. 2017b), and sulphonylurea therapy (in directly tested, see Vaccaro et al. 2017, Rosenstock et al. 2019a) are cardiovascular neutral. In this respect it is worthwhile to mention that pioglitazone has been shown to reduce relative risk for myocardial infarction and stroke in a special patient population (subgroup of the PROACTIVE trail), i.e. patients after stroke or transient ischaemic attack (Kernan et al. 2016). Cardiovascular safety studies were conducted for the DPP4 inhibitors alogliptin, linagliptin, saxagliptin and sitagliptin; there is no corresponding prospective endpoint study for vildagliptin. These endpoint studies (Zannad et al. 2015 EXAMINE, Rosenstock et al. 2019b CARMELINA, Scirica et al. 2013 SAVOR-TIMI 53, Green et al. 2015 TECOS) showed safety, but not superiority, in patients with pre-existing cardiovascular disease or multiple risk factors for the primary endpoint, which is in most cases composed of cardiovascular death, myocardial infarction and stroke. In the SAVORTIMI (Saxagliptin Assessment of Vascular Outcomes Recorded in Patients with Diabetes Mellitus-Thrombolysis In Myocardial Infarction) 53 trial, 16,492 patients with type 2 diabetes and manifest cardiovascular disease or risk factors were randomised and followed up for a mean of 2.1 years. The primary endpoint, i.e. cardiovascular safety, was proven. However, compared to placebo, a higher hospitalisation due to heart failure was observed in the treatment group with $3.5 \%$ vs. $2.8 \%$. For this reason, saxagliptin is not recommended in patients with pre-existing heart failure. Thus, GLP-1-RAs have shown to be cardiovascular protective and SGLT-2 inhibitors provide consistent evidence for cardio- and nephroprotection. Therefore, we will focus on the clinical evidence and potential mechanisms related to these observations.

\section{GLP-1 Receptor Agonists (GLP-1-RA)}

Therapeutically used GLP (glucagon like peptide)-1 receptor agonists act directly via the GLP-1 receptor, which leads not only to a glucose-dependent metabolically mediated release of insulin from the beta cells, but also to inhibition of glucagon release from the pancreatic alpha cells. Most of them are injected subcutaneously once daily or weekly, depending on the preparation. In addition to effective HbAlc lowering, this therapy also leads to clinically relevant weight loss.

The cardioprotective evidence for GLP1 receptor agonists is based on the results of 7 placebo controlled endpoint trials: LEADER for liraglutide (Marso et al. 2016b); SUSTAIN-6 for subcutaneous semaglutide (Marso et al. 2016a), HARMONY for albiglutide (Hernandez et al. 2018), REWIND for dulaglutide (Gerstein et al. 2019a), and AMPLITUDE-O for efpeglenatide (Gerstein et al. 2021). These trials demonstrated a significant reduction in the 3-point MACE endpoint (cardiovascular death, nonfatal myocardial infarction, or nonfatal stroke). In the PIONEER6 study with oral semaglutide, the primary endpoint was negative, but cardiovascular 
death and all-cause mortality were reduced (Husain et al. 2019). In the studies with lixisenatide (Pfeffer et al. 2015) and long acting formulation (LAR) of exenatide (Holman et al. 2017a), the primary endpoint was negative. The clinical results of these trials compared with placebo are summarised in Table 1. The results appear heterogeneous for the individual endpoints, which could be due to the study design and different patient populations. Effects on a reduction in the hospitalisation rate due to heart failure were not observed in any study (Lim et al. 2018). Since the curves between treatment and placebo generally only began to diverge after about 1 year, it is assumed that the cardioprotective effects are rather due to a modulation of atherosclerotic processes (Marx and Libby 2018), see Fig. 1.

In Fig. 1, we have distinguished between direct and indirect mechanisms, which we cannot discuss in detail here and therefore refer to recent reviews (Drucker 2016, Nauck et al. 2017; Müller et al. 2019, Giorgino et al. 2020, Nauck et al. 2020). In case of indirect mechanisms, the reduction of blood pressure and weight are certainly in the foreground, whereby interestingly, ectopic lipid accumulation in the liver (Armstrong et al. 2016; Newsome et al. 2021) and epicardial fat (Iacobellis and Villasante Fricke 2020) is also reduced, see below. In addition, there are first indications that certain intraepithelial $\mathrm{T}$ lymphocytes in the intestine modulate metabolism and the risk of atherosclerosis as well as that GLP-1 could play an important role as a mediator (He et al. 2019). In terms of direct mechanisms, it must be emphasised that endothelial function, plaque stabilisation and anti-inflammatory effects are of particular importance for the clinical risk posed by plaque (Libby and Hansson 2019). All these mechanisms can be modified by incretin hormones in experimental studies. Therefore, it is thought that GLP-1 receptor agonists may also directly influence the development and stability of atherosclerotic plaque (Rakipovski et al. 2018; Kahles et al. 2018). For example, GLP-1-receptors in various plaque cells like endothelial cells, vascular smooth muscle cells, monocytes, and macrophages are coupled to responses which might modulate plaque biology (Nauck et al. 2020). Similar to ROS formation, oxLDL activation of inflammatory cells and adhesion molecules are reduced. eNOS formation in endothelial cells is increased. After GLP-1- receptor stimulation, foam cell formation is reduced as well as their caspase-mediated apoptosis and the necrotic core in plaque. Interestingly, GLP-1 receptor agonist treatment of cells reduced MMP expression, potentially leading to less degradation of extracellular matrix and thereby increased plaque stability. It is also interesting that GLP-1 receptor agonists may favourably influence the consequences of an ischaemic event (Giblett et al. 2016; Brott 2015; McCormick et al. 2015).

In addition, reduction in progression of chronic kidney disease and clinical renal endpoints were positive as secondary endpoints in LEADER (Mann et al. 2017) and REWIND (Gerstein et al. 2019b). This effect might relate to GLP-1-RA treatmentassociated reduction in the progression of albuminuria and mild natriuresis possibly by some inhibition of NHE-3 in the tubulus system. 


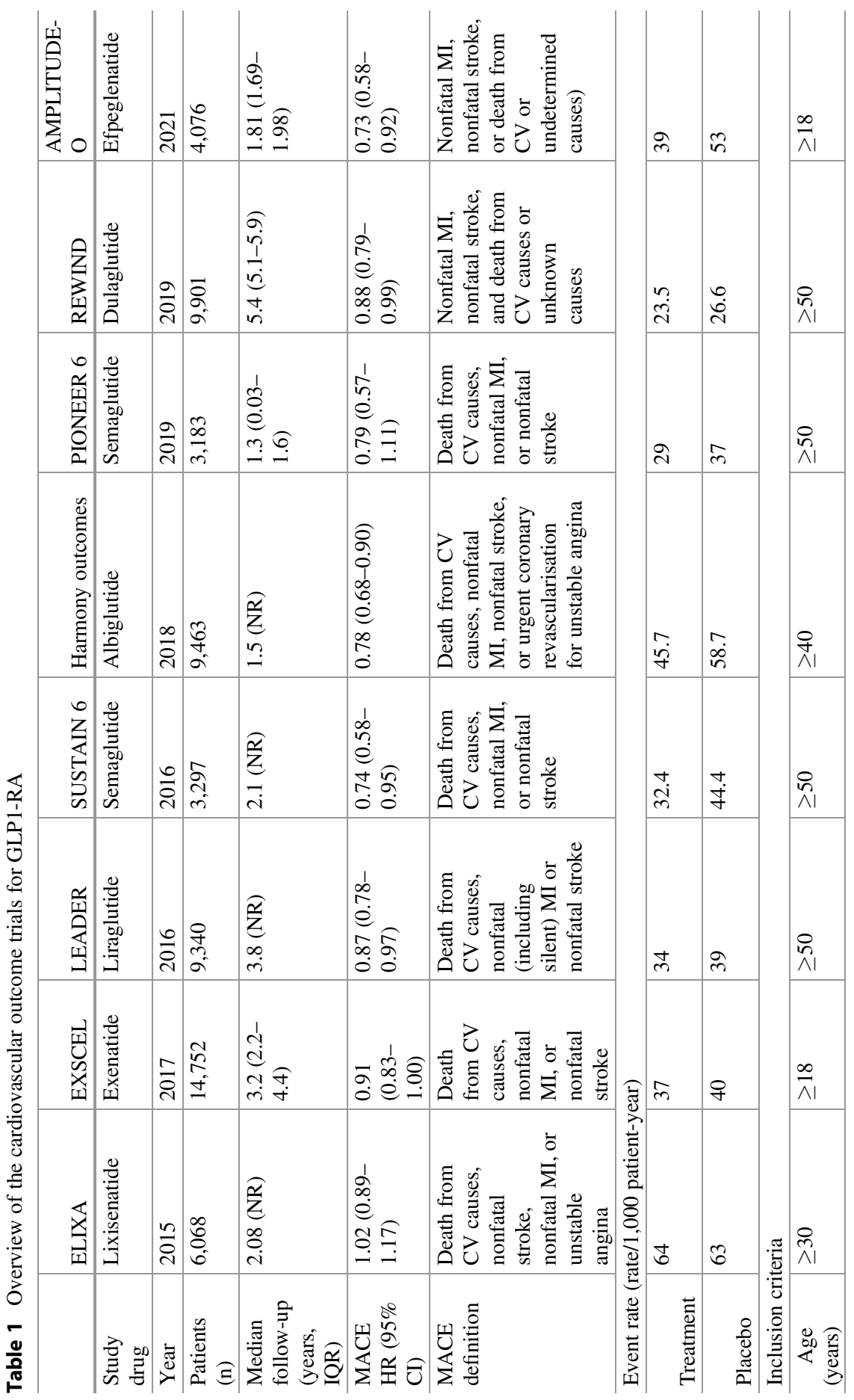




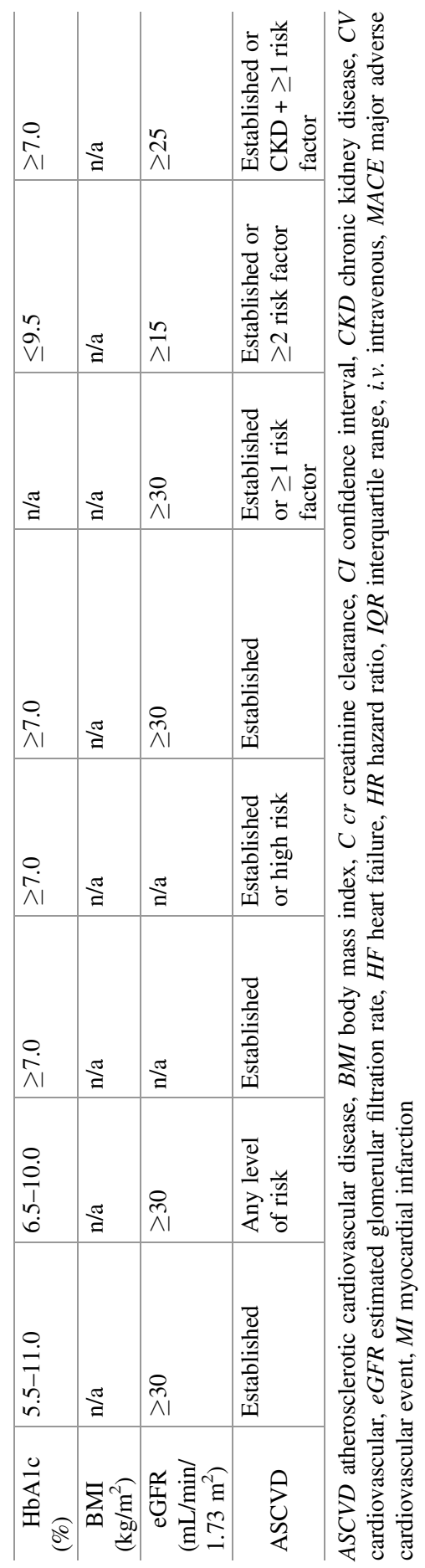




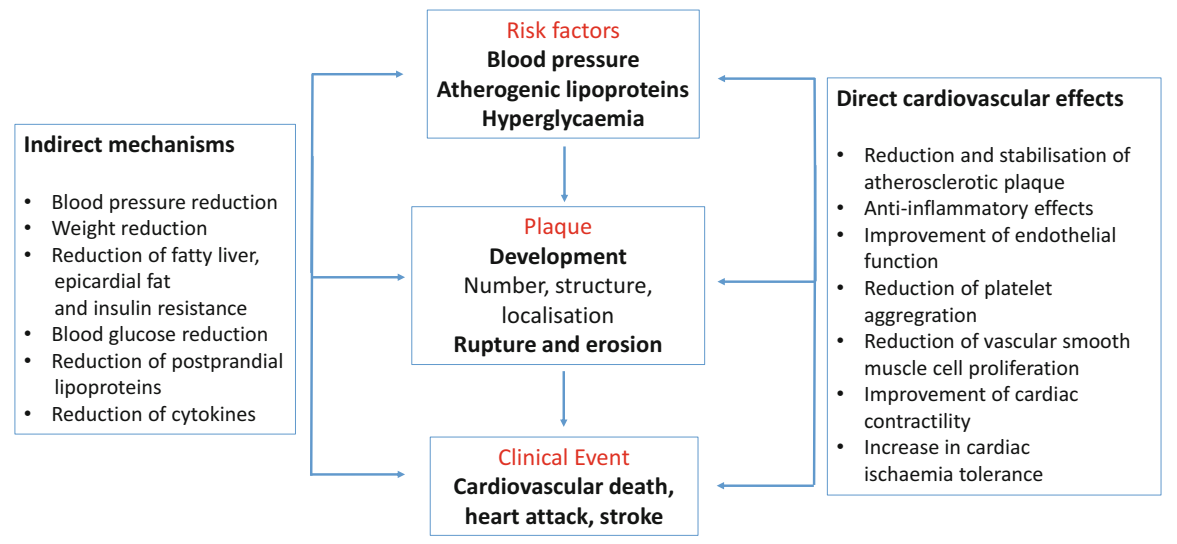

Fig. 1 Potential mechanisms and concepts for modulation of atherosclerotic plaque formation, rupture and erosion and their cardiovascular consequences by GLP-1 receptor agonists. For further explanation see text

\section{SGLT (Sodium Glucose Transporter) 2 Inhibitors}

SGLT-2 inhibitors are a group of blood glucose-lowering substances that lead to an increased excretion of glucose in the urine by reducing the activity of the transporter selectively in the proximal tubulus of the kidney by approximately 40-60\%. CVOTs have been published for canagliflozin, dapagliflozin, empagliflozin, ertugliflozin, and sotagliflozin, mentioned here in alphabetical order and are summarised in Table 2.

The EMPA-REG OUTCOME study (Zinman et al. 2015) enrolled 7,020 patients with pre-existing cardiovascular disease over a mean observation period of 3.1 years and investigated the effect of 10 or $25 \mathrm{mg}$ empagliflozin daily in addition to existing medication. The primary endpoint was a composite of cardiovascular death and nonfatal myocardial infarction and stroke and was significantly reduced with a relative risk reduction (RRR) of $14 \%$; the event rate was $12.1 \%$ in the placebo group and $10.5 \%$ with empagliflozin treatment. There was no difference between the two doses of empagliflozin. Component analysis showed no effect on nonfatal myocardial infarction or stroke, but cardiovascular mortality was significantly reduced with an RRR of $38 \%$, which also reduced all-cause mortality. In addition, hospitalisation due to heart failure was also significantly lower with an RRR of $35 \%$, an effect that became significant after only a few weeks. The effect on renal function was further analysed. The prespecified secondary renal endpoint was worsening nephropathy (progression to macroalbuminuria, doubling of serum creatinine, initiation of renal replacement therapy or death due to renal causes) and incidence rate of albuminuria. The incidence or relative risk of worsening nephropathy was significantly reduced by $44 \%$ with empagliflozin (Wanner et al. 2016). In the primary CANVAS programme (Neal et al. 2017) and in the CREDENCE study (Perkovic 


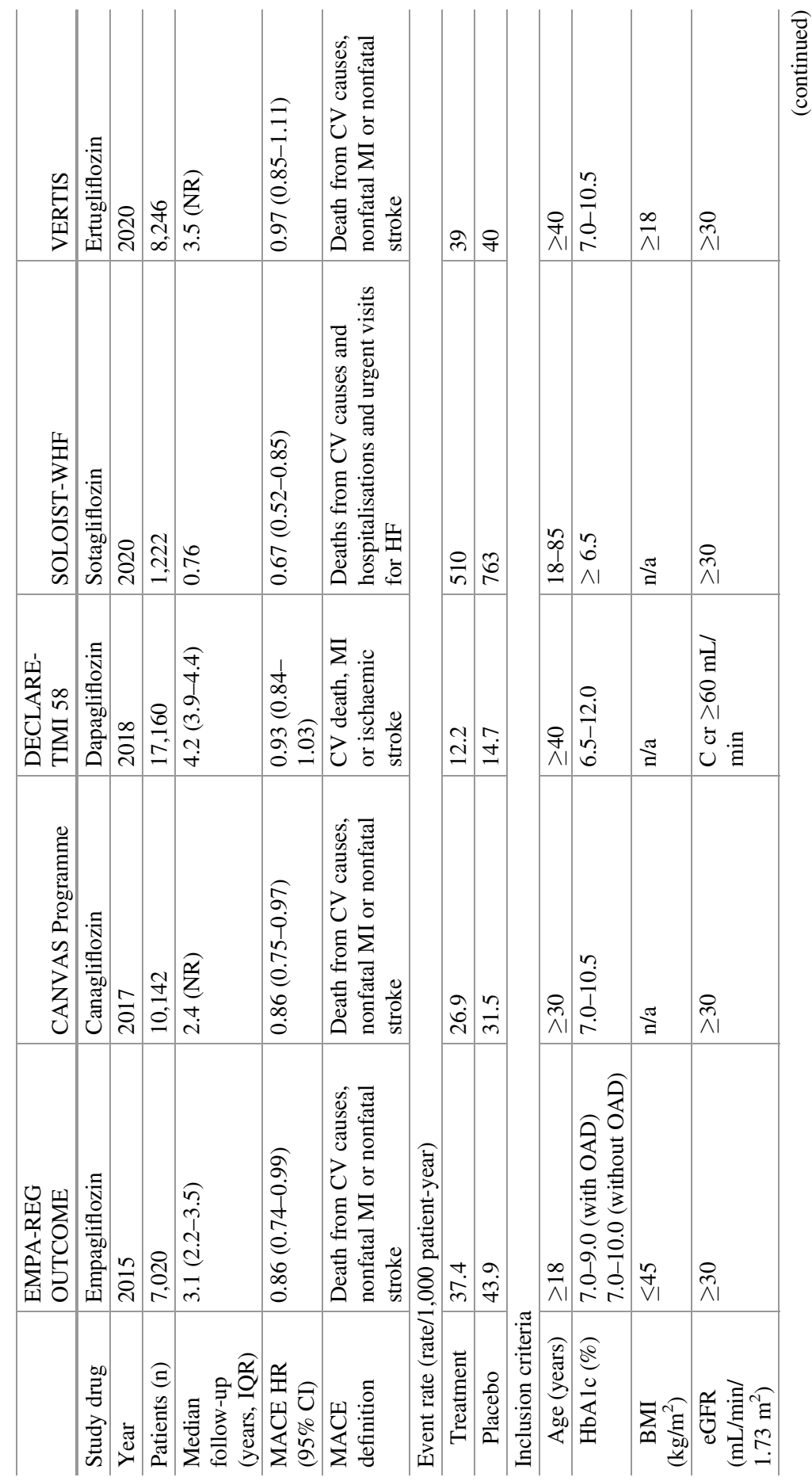




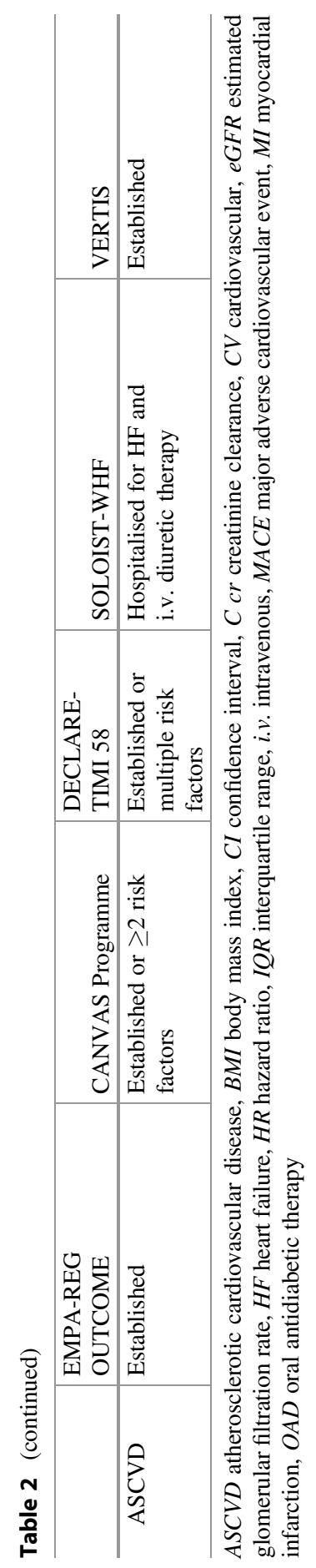


et al. 2019), the SGLT-2 inhibitor canagliflozin also significantly reduced the risk of the combined cardiovascular endpoint (cardiovascular death, nonfatal myocardial infarction or stroke) by $14 \%$ and renal endpoints. This confirmed the concept of cardio-renal risk reduction by a second substance, and the question now arose whether this principle of action could also be observed with a third substance and, above all, also in patients with lower cardio-renal risk. In the DECLARE-TIMI 58 trial, 17,160 patients with type 2 diabetes were studied over a mean of 4.2 years with and without dapagliflozin $10 \mathrm{mg} ; 10,186$ of these patients had no previous atherosclerotic disease (Wiviott et al. 2019). The primary safety analysis confirmed non-inferiority of dapagliflozin for MACE (major cardiovascular events), and the primary efficacy analysis showed a significantly lower event rate for the combined endpoint of cardiovascular death and hospitalisation for heart failure (HHF), although this outcome was substantially driven by HHF. A sub-analysis of 3,586 patients with pre-existing myocardial infarction showed that compared with placebo, dapagliflozin significantly reduced the relative risk of MACE by $16 \%$ with an absolute risk reduction of $2.6 \%$ (Furtao et al. 2019). The effect of dapagliflozin on nephropathy has been investigated as a renal composite secondary endpoint $(\geq 40 \%$ decrease in eGFR in $\mathrm{mL} / \mathrm{min} / 1.73 \mathrm{~m}^{2}$, new manifestation of ESRD, or death due to renal or cardiovascular causes). The relative risk for this renal endpoint was significantly reduced by $24 \%$ with dapagliflozin. In the 671 patients with heart failure and impaired left ventricular pump function, dapagliflozin also significantly reduced not only hospitalisation for heart failure but also cardiovascular death with a relative risk reduction of $45 \%$ compared to placebo (Kato et al. 2019). Ertugliflozin was investigated in the VERTIS CV trial in 8246 patients with type 2 diabetes and cardiovascular disease over a mean of 3.5 years (Cannon et al. 2020). Ertugliflozin was noninferior to placebo for MACE and clinical renal endpoints. However, results were consistent with other SGLT2-inhibitors in respect of reducing hospitalisation for heart failure in a respective prespecified group and reduction in decline rate of eGFR. Sotagliflozin, an SGLT2 inhibitor with possibly some SGLT-1 blocking potential, was investigated in patients with diabetes and recent worsening of heart failure (SOLOIST-WF) and in patients with diabetes and chronic kidney disease (SCORED) resulting in a significant risk reduction for cardiovascular death and hospitalisation for heart failure in patients with heart failure (Bhatt et al. 2020b) or chronic kidney disease with or without albuminuria (Bhatt et al. 2020a).

In consideration of these very impressive trial results with major impact on risk for heart failure and renal complications to a large extent non-related to baseline $\mathrm{HbA1c}$ and glucose-lowering capacity in these trials, the question was emerging, whether SGLT2-inhibitors reduce also clinical risk primarily in patients suffering from chronic heart failure or kidney disease with and also without diabetes. Four studies have been published so far, the DAPA-HF and EMPEROR-Reduced trials for chronic heart failure and CREDENCE for patients with chronic kidney disease (CKD) in patients with diabetes and the DAPA-CKD trial in CKD patients with and also without diabetes.

In the DAPA-HF study (McMurray et al. 2019), 4,744 patients with manifest heart failure and impaired left ventricular function (LVEF $\leq 40 \%$, NT-proBNP 
$\geq 600 \mathrm{pg} / \mathrm{mL}$ ) were enrolled and treated with dapagliflozin $10 \mathrm{mg}$ or placebo in addition to existing standard therapy. The study was event-driven and ran for approximately 3 years. The relative risk for the primary endpoint was significantly reduced by $26 \%$ and was composed of cardiovascular death, hospitalisation or urgent medical visit for heart failure. There was no difference between the $42 \%$ of patients with or without diabetes. In the EMPEROR-Reduced trial (Packer et al. 2020) 3730 patients with chronic heart failure and reduced left ventricular ejection fraction $(\leq 40 \%)$ were investigated over a mean period of 16 months. The relative risk for the primary combined endpoint being cardiovascular death and hospitalisation for heart failure was significantly reduced by $25 \%$ regardless of the presence or absence of diabetes. Therefore, both studies show the benefit of SGLT2inhibition in patients with clinically relevant chronic heart failure independent of diabetes status. These data have an impacted current guidelines for the treatment of patients with chronic heart failure, SGLT2-inhibition being an evidence-based treatment option.

In patients with chronic kidney disease, CREDENCE (Perkovic et al. 2019) was the first study to investigate the effect of an SGLT-2 inhibitor, in this case $100 \mathrm{mg}$ canagliflozin OD, primarily on renal function. The primary renal endpoint was composed of end-stage renal failure (defined by need for dialysis, kidney transplantation or drop in eGFR to $<15 \mathrm{~mL} / \mathrm{min} / 1.73 \mathrm{~m}^{2}$ ), doubling of serum creatinine levels or death due to renal or cardiovascular causes. 4,401 patients with type 2 diabetes, an eGFR between 30 and $90 \mathrm{~mL} / \mathrm{min} / 1.72 \mathrm{~m}^{2}$ and albuminuria of $>300-5,000 \mathrm{mg} / \mathrm{g}$ creatinine were included and studied for a mean of 2.62 years. Canagliflozin significantly reduced the relative risk for the primary renal endpoint by $30 \%$, the relative risk for end-stage renal failure by $32 \%$ and its combination with creatinine doubling and renal death by $34 \%$. DAPA-CKD (Heerspink et al. 2020) randomly assigned 4,304 patients with an eGFR of $25-75 \mathrm{~mL} / \mathrm{min} / 1.73 \mathrm{~m}^{2}$ and a urinary albumin-to-creatinine ratio of 200-5,000 receiving $10 \mathrm{mg}$ dapagliflozin or placebo over a median time of 2.4 years. The relative risk for the combined endpoint of sustained decline in the eGFR of at least $50 \%$, end-stage kidney disease, or death from renal causes was significantly lower by $44 \%$ in the dapagliflozin arm compared to the placebo group. This effect was irrespective of having type 2 diabetes or not. Therefore, SGLT-2 inhibitors are also finding their position in guidelines for the treatment of chronic kidney disease. However, one should be aware that currently there are still differences in specifications of their label in patients with reduced eGFR in different countries and regions of the world.

\section{Mechanisms of Action for Cardio-Renal Protection Through SGLT-2 Inhibition}

SGLT-2 transports glucose in exchange for sodium in the proximal tubule of the kidney and reabsorbs approximately $90 \%$ of the $180 \mathrm{~g}$ of glucose normally filtered daily in primary urine, for review see Heerspink et al. (2016); Lytvyn et al. (2017); Verma and McMurray (2018); Marton et al. (2021). SGLT-2 inhibitors selectively 
SGLT-2 inhibitors: Potential mechanisms for cardiac protection

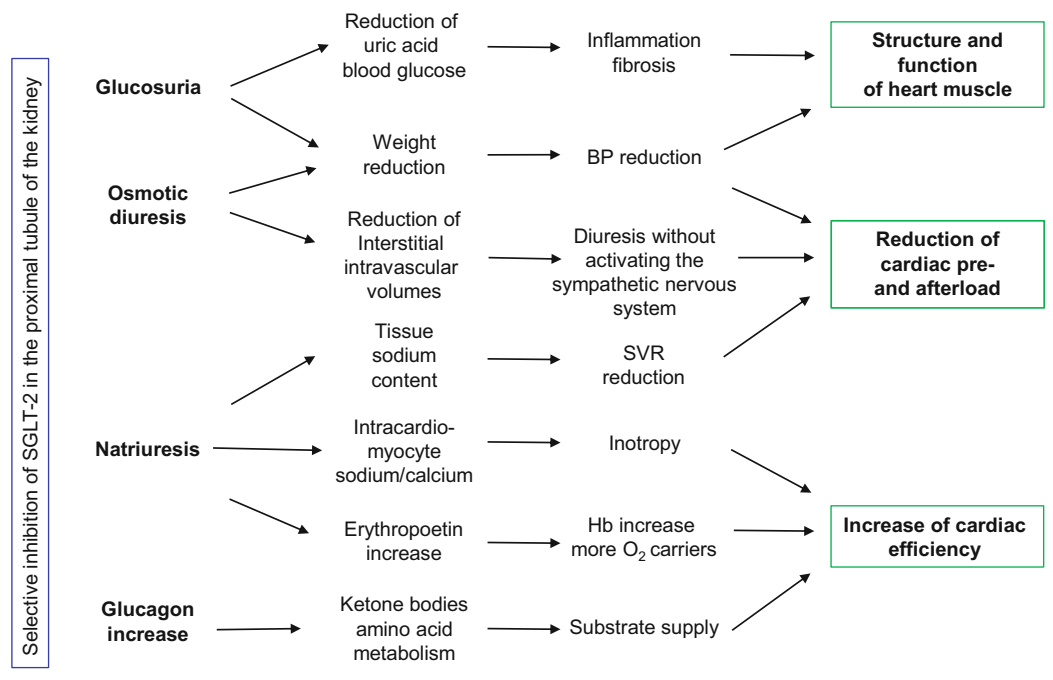

Fig. 2 Potential mechanisms and concepts of cardiac protection by SGLT-2 inhibitors. For further explanation see text

prevent the transporter with high affinity by an average of about $40-60 \%$. This inhibition leads to glucosuria, associated osmotic diuresis, increased natriuresis and an increase in glucagon levels. Figure 2 summarises the principal mechanisms of action and outlines how the cardioprotective effects associated with SGLT-2inhibitor therapy are currently imagined.

Glucosuria leads to a loss of calories, approx. $70-80 \mathrm{~g}$ over $24 \mathrm{~h}$, corresponding to approx. $300 \mathrm{kcal}$, and weight reduction of approx. $2-3 \mathrm{~kg}$, half of which is due to the reduction of fat mass. The other half is due to the osmotic diuresis of approx. $300 \mathrm{~mL} / 24 \mathrm{~h}$. In contrast to diuretics, this, in combination with natriuresis, leads to an interstitial fluid mobilisation without a significant reduction in intravascular volume, and thus not to an activation of the sympathetic nervous system or an increase in the pulse rate. These effects also cause a reduction in peripheral vascular resistance and, in combination, a reduction in blood pressure of 4-6 $\mathrm{mmHg}$ systolic (1-2 mmHg diastolic), which can be even more pronounced at elevated blood pressure levels or in combination with diuretics.

In addition, natriuresis and possibly direct interaction of SGLT-2 inhibitors in the myocardium with sodium proton exchanger-1 (NHE-1) may favourably alter the intracellular ratio of sodium and calcium. The increased natriuresis, also through additional inhibition of tubular NHE-3, probably leads indirectly in the medulla of the kidney to higher consumption of oxygen and thus renally to an increased formation of erythropoietin and an increase in the formation of red blood cells and the oxygen carrier haemoglobin. In a mediation analysis of the cardiovascular 
endpoint study of empagliflozin, this appears to be clinically relevant for understanding the observed effect in cardioprotection (Inzucchi et al. 2018).

An increase in glucagon levels of about twofold by SGLT-2 inhibitors is associated with an approximately twofold increase in the concentration of ketone bodies during therapy. Ketone bodies in turn can be effective substrates (especially $\alpha$-hydroxy-butyrate) for cardiac muscle and possibly also lead to altered metabolism of branched-chain amino acids in the cardiac muscle, which can be disturbed in diabetic cardiomyopathy (Wanner and Marx 2018). In summary, therapy with SGLT-2 inhibitors results in a rapid and effective pre- and afterload reduction of the heart as well as possibly a clinically relevant favourable change in metabolism and intracardiomyocyte electrolytes, stabilising the structure and function of the myocardium and increasing work efficiency.

For renoprotection, the key mechanism is probably increased natriuresis in the proximal tubule, leading to activation of the tubuloglomerular feedback (TGF) mechanism. The natriuresis caused by SGLT2 inhibition is sensed by the macula densa in the juxtaglomerular apparatus and leads to a counter-regulation, i.e. specifically a reduction of glomerular filtration by constriction of the vas afferens, probably mediated by adenosine. This lowers the intraglomerular pressure and thus also leads to a reduction in albuminuria and in the long term to a stabilisation and reduced progressive decrease in the glomerular filtration rate. This fascinating observation now also makes the hyperfiltration in the early phase of a renal change in patients with diabetes understandable, because an increased activity of the SGLT2 transporter in diabetes leads to increased reabsorption of sodium, thus reduction of TGF and vasodilation of the vas afferens and thus hyperfiltration of the glomerulum.

In addition to the aforementioned hypotheses of reduction of cardiac pre-and after-load and intraglomerular pressure reduction by tubuloglomerular feedback mechanisms, a recent hypothesis involves metabolic adaptations. Under SGLT-2inhibitor treatment, there is an increased caloric loss and an about twofold increase in glucagon levels with a consecutive increase in ketone bodies. These endocrinemetabolic changes provide both a better energy efficient substrate utilisation for the heart and the metabolism switch to a state of chronic hypometabolism and water deprivation. This state is compensated in the long-run by appropriate adaptation of energy homeostasis or metabolic rate and water conservation. This adaptation process, called "aestivation", is evolutionary conserved enabling adaptation to energy and water shortage (Marton et al. 2021). This metabolic switch induced by SGLT-2-inhibition might play a role in improved function and reduced damage progression of different organs, most extensively clinically proven for heart and kidney.

\section{Change in Guidelines and Clinical Recommendations}

Patient-centred care is the focus of most guidelines and new recommendations (Davies et al. 2018; Consentino et al. 2019; Buse et al. 2020; Landgraf et al. 2020; American Diabetes Association 2021). Based on the clinical evidence provided 
recently and discussed above, guidelines nowadays don't put HbA1c in focus for decision about treatment strategy in type 2 diabetes, but rather the clinical picture and risk of cardio-renal complications in the foreground. Evidence-based means that the results of large studies, especially cardiovascular endpoint studies, must be translated into practice.

The recent ESC recommendations on "Diabetes, prediabetes and cardiovascular disease" (Consentino et al. 2019), produced in collaboration with the EASD, have incorporated the extensive data from large cardiovascular endpoint studies in recent years with new antidiabetic agents and have led to a new and more specific positioning of metformin and cardioprotective blood glucose-lowering drugs in patients with high and very high cardio-renal risk and diabetes mellitus. The decisive factor for the choice of a glucose-lowering substance for cardiovascular risk reduction is primarily not an HbA1c target anymore, but the risk stratification of patients with diabetes according to the ESC recommendations 2019:

Very high risk patients are those with diabetes and established cardiovascular disease or end organ damage or three or more risk factors or early onset of type 1 diabetes of long duration ( $>20$ years). Patients with diabetes duration $\geq 10$ years without end-organ damage but with another risk factor are classified in the high risk category. The moderate-risk category includes young patients (type 1 diabetes under 35 or type 2 diabetes under 50 years) with diabetes duration under 10 years without other risk factors.

The new algorithm for cardiovascular risk reduction with antihyperglycaemic agents in untreated type 2 diabetic patients - regardless of HbA1c level - focuses on the high/very high risk categories. Patients with atherosclerotic cardiovascular disease or high/very high risk should receive an SGLT2 inhibitor or GLP1 receptor agonist monotherapy as a class Ia recommendation, according to the evidence from the studies above. In patients with existing or increased risk for heart failure, SGLT2 inhibitors are recommended. Similar recommendation belongs to renal protection.

Although the effect of metformin on risk for myocardial infarction was better than expected from degree of glucose lowering in the UKPS trial, it has been questioned whether metformin should continue to be first-line therapy in all patients with type 2 diabetes. The CVOTs described above suggest that in these patient groups GLP-1 RAs and SGLT2-inhibitors should be first choice driven by evidence and not metformin. This is supported by further evaluations of these CVOTs indicating that metformin has no modulating effect on risk protection by GLP-1RA or SGLT2-inhibitors (Marx 2020; Sattar and McGuire 2021).

\section{Perspectives: Fat Partitioning as a New Target of Diabetes Drugs}

Like treatment of chronic heart failure or chronic kidney disease in patients with and without diabetes by SGLT2-inhibitors initially developed for diabetes, it is also interesting to note that new incretin-based drugs, like "twincretins", reach mean body weight reductions between 8 and $12 \mathrm{~kg}$ and absolute reductions in HbA1c of 
around 2.0\% (Rosenstock et al. 2021; Frías et al. 2021). Results of these kind of studies might help decipher new networks between fat tissue, diabetes and atherosclerosis related risks. In this respect, increased and abnormally distributed fat might be a new target. Numerous clinical and pathogenetic studies have changed our understanding of adipose tissue in such a way that the amount of adipose tissue is not the only essential pathophysiological phenomenon, but in particular the abnormal deposition of fat in other cells or organs, called ectopic lipid accumulation or fat partitioning (Blüher 2016; Crewe et al. 2017; Scherer 2016; Stefan et al. 2008; Unger 2002). When the normal storage capacity and plasticity of subcutaneous adipose tissue and its ability to adapt to increased energy balance are exhausted, there is recruitment of inflammatory cells in adipose tissue and increased deposition of fat in other cells, such as visceral fat cells, and in cells of the liver and cardiovascular system. The deposition of fat alters the function of these cells, e.g. resistance to insulin in the liver, release of mediators from visceral fat, or possibly changes in contractility in the case of cardiac muscle cells. A clinically important and classic example of ectopic lipid accumulation is Non-Alcoholic Fatty Liver Disease (NAFLD), which is often associated with insulin resistance, obesity and diabetes (van Heerebeek and Paulus 2016) and diastolic dysfunction of the heart (van Wagner et al. 2015). A growing number of studies show that intracardiomyocyte fat is associated with altered cardiac cell function including heart failure and epicardial fat (EAT) cells may influence cardiac function and cardiovascular risk through release of humoral, inflammatory and metabolic mediators (Unger 2002; McGavock et al. 2007; Fontes-Carvahlo et al. 2014). Recently it has been shown that in patients with diabetes EAT volume was independently associated with coronary calcium score (Cosson et al. 2021) and that extracellular vesicles from EAT facilitate atrial fibrillation and induce proinflammatory and fibrotic responses in cell culture (Shaihov-Teper et al. 2021). Furthermore, considering potential cardiovascular benefit of greater weight reductions, as we have learned from bariatric surgery (Sjöström et al. 2004), CVOTs of these new treatment options are awaited with great curiosity. In addition, these degrees of fat reduction and glucose-lowering open up possibilities to reach "remission" of type 2 diabetes (Lean et al. 2018). Overall perspectives in the treatment of type 2 diabetes are to identify different subgroups with different risk profiles for late complications and to better understand major pathomechanisms that can then be therapeutically targeted therapeutically (Ahlquist et al. 2019; Zaharia et al. 2019).

\section{References}

Ahlquist E, Tuomi T, Groop L (2019) Clusters provide a better holistic view of type 2 diabetes than simple clinical features. Lancet Diabetes Endocrinol 7:668-669

American Diabetes Association (2021) Standards in medical care in diabetes - 2021. Pharmacological approaches to glycaemic treatment. Diabetes Care 44(Suppl 1):S111-S125

Armstrong MJ, Gaunt P, Aithal GP et al (2016) Liraglutide safety and efficacy in patients with non-alcoholic steatohepatitis (LEAN): a multicentre, double-blind, randomised, placebocontrolled phase 2 study. Lancet 387:679-690 
Battelino T, Danne T, Bergenstal RM et al (2019) Clinical targets for continous glucose monitoring data interpretation: recommendations from the international consensus on time in range. Diabetes Care 42:1593-1603

Bebu I, Braffett BH, Orchard TJ et al (2019) Mediation of the effect of glycemia on the risk of CVD outcomes in type 1 diabetes: the DCCT/EDIC study. Diabetes Care 42:1284-1289

Bhatt DL, Szarek M, Pitt B et al (2020a) Sotagliflozin in patients with diabetes and chronic kidney disease. N Engl J Med. https://doi.org/10.1056/NEJMoa2030186

Bhatt DL, Szarek M, Steg PG et al (2020b) Sotagliflozin in patients with diabetes and recent worsening heart failure. N Engl J Med. https://doi.org/10.1056/NEJMoa2030183

Blüher M (2016) Adipose tissue inflammation: a cause or consequence of obesity-related insulin resistance? Clin Sci 130:1603-1614

Brott BC (2015) Prevention of myocardial stunning during percutaneous coronary interventions: novel insights from pre-treatment with glucagon-like peptide-1. JACC Cardiovasc Interv 8:302-304

Brownrigg JRW, Hughes CO, Burleigh D et al (2016) Microvascular disease and risk of cardiovascular events among individuals with type 2 diabetes: a population-level-cohort study. Lancet Diabetes Endocrinol 4:588-597

Buse JB, Wexler DJ, Tsapas A et al (2020) 2019 update to: Mangement of hyperglycemia in type 2 diabetes, 2018. A consensus report by the American Diabetes Association (ADA) and the European Association fort he Study of Diabetes (EASD). Diabetologia 63:221-228 and Diabetes Care 43:487-493

Cannon CP, Pratley R, Dagogo-Jack S et al (2020) Cardiovascular outcomes with ertugliflozin in type 2 diabetes. N Engl J Med 383:1425-1435

Climie RE, Gallo A, Picone DS et al (2019) Measuring the interaction between the macro- and micro-vasculature. Front Cardiovasc Med. https://doi.org/10.3389/fcvm.2019.00169

Consentino F, Grant PJ, Aboyans V et al (2019) 2019 ESC guidelines on diabetes, pre-diabetes, and cardiovascular diseases developed in collaboration with the EASD. Eur Heart J. https://doi.org/ 10.1093/eurheartj/ehz486

Cosson E, Nguyen MT, Rezgani I et al (2021) Epicardial tissue volume and coronary calcification among people living with diabetes: a cross-sectional study. Cardiovasc Diabetol 20:35. https:// doi.org/10.1186/s12933-021-01225-6

Crewe C, An YA, Scherer PE (2017) The omnious triad of adipose tissue dysfunction: inflammation, fibrosis, and impaired angiogenesis. J Clin Invest 127:74-82

Danesh J for The Emerging Risk Factors Collaboration (2015) Association of cardiometabolic multimorbidity with mortality. JAMA 314:52-60

Davies MJ, DÁlessio DA, Fradkin J, Kernan WN, Mathieu C, Mingrone G, Rossing P, Tsapa A, Wexler DJ, Buse JB (2018) Management of hyperglycemia in type 2 diabetes, 2018. A consensus report by the American Diabetes Association (ADA) and the European Association for the Study of Diabetes EASD. Diabetologia 61:2461-2498 and Diabetes Care 41:2669-2701

Drucker DJ (2016) The cardiovascular biology of glucagon-like peptide-1. Cell Metab 24:15-30

Duckworth W, Abraira C, Moritz T et al (2009) for the VADT Investigators. Glucose control and vascular complications in veterans with type 2 diabetes. N Engl J Med 360:129-139

Einarson TR, Acs A, Ludwig C, Panton UH (2018) Prevalence of cardiovascular disease in type 2 diabetes: a systematic literature review of scientific evidence from across the world in 20072017. Cardiovasc Diabetol 17:83. https://doi.org/10.1186/s12933-018-0728-6

Fontes-Carvahlo R, Fontes-Oliveira M, Sampaio F et al (2014) Influence of epicardial and visceral fat on left ventricular diastolic and systolic functions in patients after myocardial infarction. Am J Cardiol 114:1663-1669

Frías JP, Davies MJ, Rosenstock J et al (2021) Tirzepatide versus semaglutide once weekly in patients with type 2 diabetes. N Engl J Med. https://doi.org/10.1056/NEJMoa2107519

Furtao RHM, Bonaca MP, Raz I et al (2019) Dapagliflozin and cardiovascular outcomes in patients with type 2 diabetes mellitus and previous myocardial infarction. Subanalysis from DECLARETIMI 58 trial. Circulation 139:2516-2527 
Gerstein HC, Miller ME, Byington RP et al (2008) for The Action to Control cardiovascular Risk in Diabetes (ACCORD) Study Group. Effects of intensive glucose lowering in type 2 diabetes. $\mathrm{N}$ Engl J Med 358:2545-2559

Gerstein HC, Colhoun HM, Dagenais GR et al (2019a) Dulaglutide and cardiovascular outcomes in type 2 diabetes (REWIND): a double-blind, randomised placebo-controlled trial. Lancet 394:121-130

Gerstein HC, Colhoun HM, Dagenais GR et al (2019b) Dulaglutide and renal outcomes in type 2 diabetes: an exploratory analysis oft he REWIND randomised, placebo-controlled trial. Lancet 394:131-138

Gerstein HC, Sattar N, Rosenstock J et al (2021) Cardiovascular and renal outcomes with efpeglenatide in type 2 diabetes. N Engl J Med. https://doi.org/10.1056/NEJMoa2108269

Giblett JP, Clarke SJ, Dutka DP, Hoole SP (2016) Glucagon-like peptide-1: a promising agent for cardioprotection during myocardial ischemia. JACC Basic Transl Sci 1:267-276

Giorgino F, Caruso I, Moellmann J, Lehrke M (2020) Differential indication for SGLT-2 inhibitors versus GLP-1 receptor agonists in patients with established atherosclerotic heart disease or at risk for congestive heart failure. Metabolism 104:154045

Green JB, Bethel MA, Armstrong PW et al (2015) Effect of sitagliptin on cardiovascular outcomes in type 2 diabetes. N Engl J Med 373:232-242

He S, Kahles F, Rattik S et al (2019) Gut intraepithelial T cells calibrate metabolism and accelerate cardiovascular disease. Nature 566:115-119

Heerspink HJL, Perkins BA, Fitchett DH et al (2016) Sodium glucose cotransporter-2 inhibitors in the treatment of diabetes mellitus. Circulation 134:752-772

Heerspink HJL, Stefansson BV, Correa-Rotter R et al (2020) Dapagliflozin in patients with chronic kidney disease. N Engl J Med 383:1436-1446

Heller SR on behalf oft he ADVANCE collabrative group (2009) A summary oft he ADVANCE trial. Diabetes Care 32(Suppl 2):S357-S361

Hernandez AF, Green JB, Janmohamed S et al (2018) Albiglutide and cardiovascular outcomes in patients with type 2 diabetes and cardiovascular disease (Harmony Outcomes): a double-blind, randomised placebo-controlles trial. Lancet 392:1519-1529

Holman RR, Bethel MA, Mentz RJ et al (2017a) Effects of once-weekly exenatide on cardiovascular outcomes in type 2 diabetes. N Engl J Med 377:1228-1239

Holman RR, Coleman RL, Chan JCN et al (2017b) Effects of acarbose on cardiovascular and diabetes outcomes in patients with coronary heart disease and impaired glucose intolerance (ACE): a randomized, double blind, placebo-controlled trial. Lancet Diabetes Endocrinol 5:877-886

Husain M, Birkenfeld AL, Donsmark M et al (2019) Oral semaglutide and cardiovascular outcomes in patients with type 2 diabetes. $\mathrm{N}$ Engl J Med 381:841-851

Iacobellis G, Villasante Fricke AC (2020) Effects of semaglutide versus dulaglutide on epicardial fat thickness in subjects with type 2 diabetes and obesity. J Endocr Soc. https://doi.org/10.1210/ jendso/bvz042

Inzucchi SE, Zinman B, Fitchett D et al (2018) How does empagliflozin reduce cardiovascular mortality? Insights from a mediation analysis of the EMPA-REG OUTCOME trial. Diabetes Care 41:36-363

Kahles F, Liberman A, Halim C et al (2018) The incretin hormone GIP is upregulated in patients with atherosclerosis and stabilizes plaques in ApoE-/- mice by blocking monocyte/macrophage activation. Mol Metab 14:150-157

Kahn CR, Wang G, Lee KY (2019) Altered adipose tissue and adipocyte function in the pathogenesis of metabolic syndrome. J Clin Invest 129:3990-4000

Kato ET, Silverman MG, Mosenzon O et al (2019) Effect of dapagliflozin on heart failure and mortality in type 2 diabetes mellitus. Circulation 139:2528-2536

Kernan WN, Viscoli CM, Furie KL et al (2016) Pioglitazone after ischemic stroke or transient ischemic attack. N Engl J Med 374:1321-1331 
Landgraf R, Aberle J, Birkenfeld AL et al (2020) Therapie des Typ-2-Diabetes. Diabetol Stoffwechs 15(Supplement):S65-S92

Lean ME, Leslie WS, Barnes AC et al (2018) Primary care-led weight management for remission of type 2 diabetes (DiRECT): an open-label, cluster-randomised trial. Lancet 391:541-551. https:// doi.org/10.1016/S0140-6736(17)33102-1

Libby P, Hansson GK (2019) From focal lipid storage to systemic inflammation: JACC review topic of the week. J Am Coll Cardiol 74:1594-1607

Lim S, Kim KM, Nauck MA (2018) Glucagon-like peptide-1 receptor agonists and cardiovascular events: class effects versus individual patterns. Trends Endocrinol Metab 29:238-248

Lind M, Svensson A-M, Kosiborod M et al (2014) Glycemic control and excess mortality in type 1 diabetes. N Engl J Med 371:1972-1982

Lytvyn Y, Bjornstad P, Udell JA et al (2017) Sodium glucose cotransporter-2 inhibition in heart failure. Circulation 136:1643-1658

Mann JFE, Orsted DD, Brown-Frandsen K et al (2017) Liraglutide and renal outcomes in diabetes. N Engl J Med 377:839-848

Marso SP, Bain SC, Consoli A et al (2016a) Semaglutide and cardiovascular outcomes in patients with type 2 diabetes. New Engl J Med 375:1834-1844

Marso SP, Daniels GH, Brown-Frandsen K et al (2016b) Liraglutide and cardiovascular outcomes in patients with type 2 diabetes. New Engl J Med 375:311-322

Marso SP, McGuirre DK, Zinman B et al (2017) Efficacy and safety of degludec versus glargine in type 2 diabetes. N Engl J Med 377:723-732

Marton A, Kaneko T, Kovalik J-P et al (2021) Organ protection by SGLT2 inhibitors: role of metabolic energy and water conservation. Nat Rev Nephrol 17:65-77

Marx N (2020) Reduction of cardiovascular risk in patients with T2DM by GLP-1 receptor agonists: a shift in paradigm driven by data from large cardiovascular outcome trials. Eur Heart J 41:3359-3362

Marx N, Libby P (2018) Cardiovascular benefits of GLP-1 receptor agonism. JACC Basic Transl Sci 3:858-860

McCormick LM, Hoole SP, White PA et al (2015) Pre-treatment with glucagon-like Peptide-1 protects against ischemic left ventricular dysfunction and stunning without a detected difference in myocardial substrate utilization. JACC Cardiovasc Interv 8:292-301

McGavock JM, Lingvay I, Zib I et al (2007) Cardiac steatosis in diabetes mellitus: a 1H-magnetic resonance spectroscopy study. Circulation 116:1170-1175

McMurray JJV, Solomon SD, Inzucchi SE et al (2019) Dapagliflozin in patients with heart failure and reduced rejection fraction. N Engl J Med. https://doi.org/10.1056/NEJMoa1911303

Müller TD, Finan B, Bloom SR et al (2019) Glucagon-like peptide 1 (GLP-1). Mol Metab 30:72-130

Nauck MA, Meier JJ, Cavender MA et al (2017) Cardiovascular actions and clinical outcomes with glucagon-like peptide-1 receptor agonists and dipeptidyl peptidase-4 inhibitors. Circulation 136:849-870

Nauck MA, Quast DR, Wefers J, Meier JJ (2020) GLP-1 receptor agonists in the treatment of type 2 diabetes - state-of-the-art. Mol Metab. https://doi.org/10.1016/j.molmet.2020.101102

Neal B, Perkovic V, Mahaffey KW et al (2017) Canagliflozin and cardiovascular and renal events in type 2 diabetes. N Engl J Med 377:644-657

Newsome PN, Buchholtz K, Cusi K et al (2021) A placebo-controlled trial of subcutaneous semaglutide in nonalcoholi steatohepatitis. N Engl J Med 384:1113-1124

Packer M, Anker SD, Butler J et al (2020) Cardiovascular and renal outcomes with empagliflozin in heart failure. N Engl J Med 383:1413-1424

Perkovic V, Jardine MJ, Neal B et al (2019) Canagliflozin and renal outcomes in type 2 diabetes and nephropathy. N Engl J Med 380:2295-2306

Pfeffer MA, Claggett B, Diaz R et al (2015) Lixisenatide in patients with type 2 diabetes and acute coronary syndrome. N Engl J Med 373:2247-2257 
Rakipovski G, Rolin B, Nøhr J et al (2018) The GLP-1 analogs liraglutide and semaglutide reduce atherosclerosis in ApoE-/- and LDLr-/- mice by a mechanism that includes inflammatory pathways. JACC Basic Transl Sci 3:844-857

Rask-Madsen C, Kahn CR (2012) Tissue-specific insulin signaling, metabolic syndrome and cardiovascular disease. Arterioscler Thromb Vasc Biol 32:2052-2059

Rawshani A, Rawshani A, Sattar N et al (2019) Relative prognostic importance and optimal levels of risk factors for mortality and cardiovascular outcomes in type 1 diabetes mellitus. Circulation 139:1900-1912

Riddle MC, Gerstein HC (2019) The cardiovascular legacy of good glycemic control: clues about mediators from the DCCT/EDIC study. Diabetes Care 42:1159-1161

Rosenstock J, Kahn SE, Johansen OE et al (2019a) Effect of linagliptin vs glimepiride on major adverse cardiovascular outcomes in patients with type 2 diabetes. The CAROLINA randomized clinical trial. JAMA 322:1155-1166

Rosenstock J, Perkovic V, Johansen OE et al (2019b) Effect of linagliptin vs placebo on major cardiovascular events in adults with type 2 diabetes and high cardiovascular and renal risk: the CARMELINA randomized clinical trial. JAMA 32:69-79

Rosenstock J, Wysham C, Frías JP et al (2021) Efficacy and safety of a novel dual GIP and GLP-1 receptor agonist tirzepatide in patients with type 2 diabetes (SURPASS-1): a double-blind, randomised, phase 3 trial. Lancet 398:143-155. https://doi.org/10.1016/S0140-6736(21) 01324-6

Sattar N, McGuire DK (2021) Prevention of CVoutcomes in antihyperglycemic drug-naive patients with type 2 diabetes with, or at elevated risk of, ASCVD: to start or not to start with metformin. Eur Heart J 42:2574-2576

Sattar N, Rawshani A, Franzen S et al (2019) Age at diagnosis of type 2 diabetes mellitus and associations with cardiovascular and mortality risks. Circulation 139:2228-2237

Scherer PE (2016) The multifaceted roles of adipose tissue: therapeutic targets for diabetes and beyond: the 2015 banting lecture. Diabetes 65:1452-1461

Scirica BM, Bhatt DL, Braunwald E et al (2013) Saxagliptin and cardiovascular outcomes in patients with type 2 diabetes mellitus. N Engl J Med 369:1317-1326

Shaihov-Teper O, Ram E, Ballan N et al (2021) Extracellular vesicles from epicardial fat facilitate atrial fibrillation. Circulation 143:2475-2493

Sjöström L, Lindroos AK, Peltonen M et al (2004) Swedish Obese Subjects Study Scientific Group. Lifestyle, diabetes, and cardiovascular risk factors 10 years after bariatric surgery. N Engl J Med 351:2683-2693

Stefan N, Kantarzis K, Häring HU (2008) Causes and metabolic consequences of fatty liver. Endocr Rev 29:939-960

Stratton IM, Adler AI, Neil HA et al (2000) Association of glycemia with macrovascular and microvascular complications of type 2 diabetes (UKPDS 35). BMJ 321:405-412

The Diabetes Control and Complication Trial Research Group (1993) The effect of intensive treatment of diabetes on the development and progression of long-term complications in insulin-dependent diabetes mellitus. N Engl J Med 329:977-986

The Diabetes Control and Complication Trial/Epidemiology of Diabetes Interventions and Complications (DCCT/EDIC) Study Research Group (2005) Intensive diabetes treatment and cardiovascular disease in patients with type 1 diabetes. N Engl J Med 353:2643-2653

The ORIGIN Trial Investigators (2012) Basla insulin and cardiovascular and other outcomes in dysglycemia. N Engl J Med 367:319-328

U.K. Prospective Diabetes Study Group (1998) Intensive blood-glucose control with sulfonylureas or insulin compared with conventional treatment and risk of complications in patients with type 2 diabetes (UKPDS 33). Lancet 352:837-853

Unger RH (2002) Lipotoxic diseases. Annu Rev Med 53:19-36

Vaccaro O, Masulli M, Nicolucci A et al (2017) Effects on the incidence of cardiovascular events oft he addition of pioglitazone versus sulfonylureas in patients with type 2 diabetes inadequately controlled with metformin (TOSCA.IT): a randomised, multicentre trial. Lancet Diabetes Endocrinol 5:887-897 
van Heerebeek L, Paulus WJ (2016) Understanding heart failure with preserved ejection fraction: where are we today? Neth Heart J 24:227-236

van Wagner LB, Wilcox JE, Colangelo LA et al (2015) Association of nonalcoholic fatty liver disease with subclinical myocardial remodeling and dysfunction: a population-based study. Hepatology 62:773-783

Verma S, McMurray JJV (2018) SGLT2 inhibitors and mechanisms of cardiovascular benefit: a state-of-the-art review. Diabetologia 61(10):2108-2117

Wanner C, Marx N (2018) SGLT-2 inhibitors: the future treatment of type 2 diabetes mellitus and other chronic diseases. Diabetologia 61:2134-2139

Wanner C, Inzucchi SE, Lachin JM, Fitchett D, von Eynatten M, Mattheus M, Johansen OE, Woerle HJ, Broedl UC, Zinman B, EMPA-REG OUTCOME Investigators (2016) Empagliflozin and Progression of Kidney Disease in Type 2 Diabetes. N Engl J Med 375:323-334

Wiviott SD, Raz I, Bonaca MP et al (2019) Dapagliflozin and cardiovascular outcomes in type 2 diabetes. N Engl J Med 380:347-357

Zaharia OP, Strassburger K, Strom A et al (2019) Risk of diabetes-associated diseases in subgroups of patients with recent-onset diabetes: a 5-year follow-up study. Lancet Diabetes Endocrinol 7:684-694

Zannad F, Cannon CP, Cushman WC et al (2015) Heart failure and mortality outcomes in patients with type 2 diabetes taking alogliptin versus placebo in EXAMINE: a multicentre, randomised, double-blind trial. Lancet 385:2067-2076

Ziegler T, Rahmnann FA, Jurisch V, Kupatt C (2020) Atheroclerosis and the capillary network; pathophysiology and potential therapeutic strategies. Cell 50. https://doi.org/10.3390/ cells 9010050

Zinman B, Genuth S, Nathan DM (2014) The diabetes control and complications trial/epidemiology of diabetes interventions and complications study: 30th anniversary presentations. Diabetes Care 37:8

Zinman B, Wanner C, Lachin JM et al (2015) Empagliflozin, cardiovascular outcomes, and mortality in type 2 diabetes. N Engl J Med 373:2117-2128

Zucker I, Schohat T, Dankner R, Chodick G (2017) New onset diabetes in adulthood is associated with a substantial risk for mortality at all ages: a population based historical cohort study with a decade-long follow-up. Cardiovasc Diabetol 16:105. https://doi.org/10.1186/s12933-017-0583-x

Open Access This chapter is licensed under the terms of the Creative Commons Attribution 4.0 International License (http://creativecommons.org/licenses/by/4.0/), which permits use, sharing, adaptation, distribution and reproduction in any medium or format, as long as you give appropriate credit to the original author(s) and the source, provide a link to the Creative Commons license and indicate if changes were made.

The images or other third party material in this chapter are included in the chapter's Creative Commons license, unless indicated otherwise in a credit line to the material. If material is not included in the chapter's Creative Commons license and your intended use is not permitted by statutory regulation or exceeds the permitted use, you will need to obtain permission directly from the copyright holder.

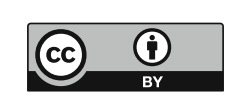

